\title{
Bakla (Vicia faba L.)'da Farklı Ekim Sıklıklarının Yaprak Alanı ve Verim Unsurlarına Etkisi
}

\author{
${ }^{*}$ Reyhan KARAYEL ${ }^{1} \quad$ Nurdoğan TOPAL ${ }^{2} \quad$ Hatice BOZOĞLU³ \\ ${ }^{1}$ Karadeniz Tarımsal Araştırma Enstitüsü, Samsun \\ ${ }^{2}$ Uşak Üniversitesi, Ziraat ve Doğa Bilimleri Fakültesi, Tarla Bitkileri Bölümü, Uşak \\ ${ }^{3}$ Ondokuz Mayıs Üniversitesi, Ziraat Fakültesi, Tarla Bitkileri Bölümü, Samsun \\ *Sorumlu yazar e-posta (Corresponding author e-mail): reyhank55@hotmail.com
}

\section{Öz}

Baklagillerin yaprak alan indeksleri yüksek, fakat ışık geçirgenlik katsayıları düşüktür. Bu nedenle gölgelenen yapraklarda fotosentez azalmakta, solunum artmasıyla asimilantların kaybı söz konusu olmaktadır. Bu çalışma farklı sıklıklarda yetiştirilen baklada yaprak alan değişimi, verim ve verime etki eden özelliklerin tespiti için planlanmıştır. Deneme iki yıl süreyle Samsun şartlarında, Filiz-99 bakla çeşidi ile 6 farklı ekim sıklığında $(25 \times 15,25 \times 25,50 \times 15,50 \times 25,75 \times 15,75 \times 25) 3$ tekrarlamalı tesadüf blokları deneme desenine göre yürütülmüştür. Veriler yıllar üzerinden birleştirilerek varysans analizi yapıımıştır. Varyans analiz sonucuna göre sıra aralıklarının bakla sayısı, gövde çapı, yüz tane ağırığı, tane verimi ve yaprak alanına; sıra üzeri mesafelerin bitki boyu, ilk bakla yüksekliği ve tane verimine; yılların bitki boyu, dal sayısı, bakla sayısı, gövde çapı, bakla uzunluğu, yüz tane ağırığı, tane verimi ve yaprakçık sayısına istatistiki olarak etki ettiği tespit edilmiştir. Farklı sıra aralığı mesafelerinde ayrı ayrı yapılan korelasyon analizi sonucu; her 3 sıra aralığında da tane veriminin bakla sayısı, gövde çapı, bakla boyu ve yüz tane ağırlığı ile pozitif ilişkili olduğu görülmüştür. Yaprak alanı ile diğer özellikler arasında $25 \mathrm{~cm}$ sıra aralığında hiçbir ilişki görülmezken, $50 \mathrm{~cm}$ sıra aralığında yaprak alanı ile gövde çapı arasında pozitif, $75 \mathrm{~cm}$ sıra aralığında yaprak alanı ile yaprakçık sayısı arasında pozitif, baklada tane sayısı ile negatif ilişki olduğu tespit edilmiştir.

Anahtar Kelimeler: Bakla, ekim sıklığı, yaprak alanı, korelasyon, path analizi

\section{Leaf Area and Yield Components Relationship of Broad Bean (Vicia faba L.) Sowed in Different Sowing Density}

\begin{abstract}
Leaf area index are high but light transmission coefficients are low in Legumes. Therefore, photosynthesis decreases in shaded leaves and loss of asimilant comes true with the increase of respiration. This study was planned to determine leaf area change, yield and properties effective on yield of broad bean sowed in different densities. Experiment was conducted in Samsun conditions for two years with Filiz-99 broad bean variety and at six different sowing densities $(25 \times 15,25 \times 25,50 \times 15,50 \times 25,75 \times 15,75 \times 25)$ according to randomized completed block design with three replications. Datas were combined over the years and variance analysis was done. According to variance analysis result, those were determined that row spacing affected pod number, stem diameter, a hundred seed weight, seed yield and leaf area; intrarow distances affected plant height, first pod height and seed yield; years affected plant height, branches number, pod number, stem diameter, pod length, a hundred seed weight, seed yield and leaflet number, statistically. As a result of correlation analysis made separately for different row spacing distances, a positive correlation between seed yield and pod number, stem diameter, pod height and a hundred seed weight was seen at three row spacing. When there was no relationship between leaf area and other features at $25 \mathrm{~cm}$ row spacing, a positive correlation was determined between leaf area and stem diameter at $50 \mathrm{~cm}$ row spacing and also for $75 \mathrm{~cm}$ row spacing leaf area had a positive correlation with leaflet number and a negative correlation with seed number in the pod.
\end{abstract}

Keywords: Broad bean, sowing density, leaf area, correlation, path analysis

\section{Giriş}

$\mathrm{B}$ akla yetiştiriciliği en eski olan kültür bitkilerindendir. Dünyanın çeşitli yerlerinde insan ve hayvan gıdası olarak yetiştirilmektedir
(Akçin 1988). Fazla miktarda vejetatif aksam üreten bakla bazen silaj yapımında da kullanılmaktadır. Ayrıca azot fiksasyonu yüksek 
olan baklanın yeşil gübre olarak toprak verimliliğinin arttırılmasında büyük önemi vardır (Özdemir 2002). Başlıca bakla üreten ülkeler Çin, Avustralya, Fransa ve İngiltere'dir. Türkiye bakla üretiminde dünyada 19. sırada yer almaktadır (FAO 2013).

Yaprak alanı karasal ekosistemlerde ışık tutma, evapotranspirasyon, fotosentez verimliliği, gübre ve sulama tepkisi gibi bitki büyüme ile ilgili çoğu fizyolojik çalışmalar için önemli bir değişkendir (Pandey and Singh 2011). Özellikle bitki sıklığı çalışmalarında yaprak alan indeksleri yüksek ancak ışık geçirgenlikleri düşük olan tane baklagil bitkilerinin yaprak alanının bilinmesi birim alan başına optimum bitki sayısını belirlemek için araştırmacıya yardımcı olur. Güneşten gelen ışık enerjisi yaprak tarafından tutulur ve fotosentezde kullanılır. Fotosentez yaprak alanı oranına bağlı olarak artar. Yaprak alanı ışık tutma, transpirasyon ve fotosentezin artmasının yanı sıra yabancı otların bastırııması için etkili özelliklerden biridir (Erdoğan 2012).

$\mathrm{Bu}$ çalışma farklı sıklıklarda yetiştirilen baklada yaprak alan değişim ve bu özelliğin tane verimi, verim unsurlarına etkisini tespit için yürütülmüştür.

\section{Materyal ve Yöntem}

Deneme, Samsun Ondokuz Mayıs Üniversitesi kampüs alanı içersinde yer alan deneme arazisinde 2 yıl süre ile yürütülmüştür. Denemenin yürütüldüğü yıllar ile uzun yıllara ait iklim verileri Şekil 1'de verilmiştir. Deneme arazisinin toprakları ise killi, tuzsuz, hafif asit, az kireçli, organik maddesi az olarak belirlenmiştir.

Denemede Filiz-99 bakla çeşidi 3 farklı sıra arası $(25,50,75 \mathrm{~cm})$ ve 2 farklı sıra üzeri $(15$, $25 \mathrm{~cm})$ mesafe olmak üzere 6 farklı sıklıkta $(25 \times 15,25 \times 25,50 \times 15,50 \times 25,75 \times 15,75 \times 25) 3$ tekrarlamalı olarak tesadüf blokları deneme deseninde ekilmiştir. Gübreleme yapılmamış yabancı ot durumuna bağlı olarak 2 kez çapa yapılmıştır. Taze hasat döneminde her parselden 5 bitkide bitki boyu, ilk bakla yüksekliği, gövde çapı, dal sayısı, yaprakçık sayısı, yaprak alanı, yaprak kuru madde oranı, sap kuru madde oranı ve bakla kuru madde oranı; kuru hasat döneminde ise 5 bitkide bakla sayısı, bakla boyu, baklada tane sayısı, 100 tane ağırlığı ve tane verimi belirlenmiştir. Yaprak alanı LI-COR 3000A Portable Area Meter ile ölçülmüştür.
Verilerin istatistik analizleri yıllar üzerinden birleştirilerek MSTAT-C paket programında yapılmış ve çoklu karşılaştırma testlerinden DUNCAN kullanıImıştır. Özellikler arası ilişkileri belirlemek için her sıra arası mesafesi için ayrı ayrı olacak şekilde korelasyon analizi yapılmıştır.
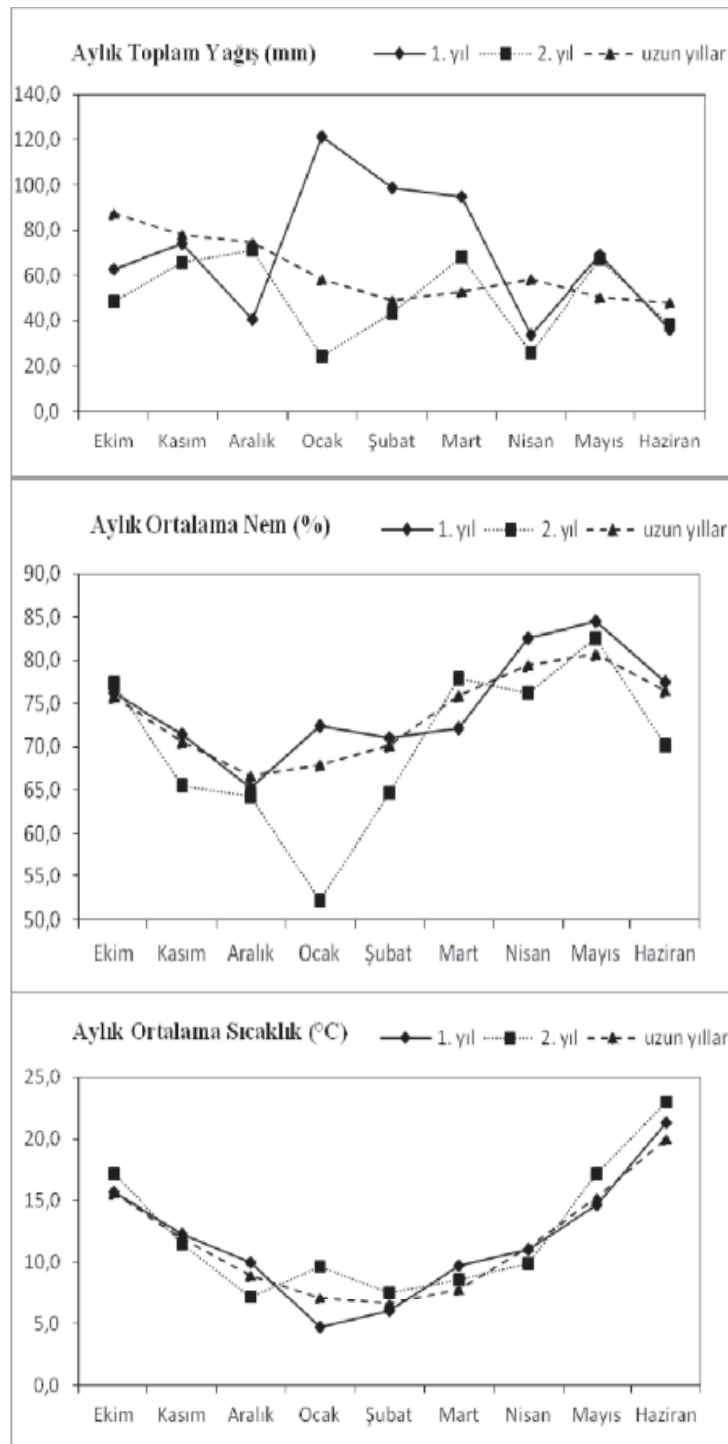

Şekil 1. Araştırma yerinin ve uzun yıllar ve denemelerin yürütüldüğü periyoduna ait a)Aylık toplam yağış miktarı (mm), b)Aylık ortalama nem (\%), c)Aylık ortalama sıcaklık değeri $\left({ }^{\circ} \mathrm{C}\right)$

Figure 1. Monthly averages of a)Total precipitation $(\mathrm{mm})$, b)Moisture content (\%) and c) Temperature $\left({ }^{\circ} \mathrm{C}\right)$ values of growing seasons with long - term averages

\section{Bulgular ve Tartışma}

Bitki sıklığı, her bitkinin mevcut alanını belirler. Çoğu bitkiler için bitki sıklığı biyokütle, tane verimi ve ekonomik karlılık üzerinde önemli bir etkiye sahiptir (Rafiei 2009; 
Albayrak ve ark. 2011; Ciampitti and Vyn 2011). Loss et al. (1998) bitki sıklığının baklada canopy yapısını, ışık dönüşüm verimliliğini, vejetatif büyüme evresini, kuru madde üretimini, tohum verimini ve sonuçta bir ürünün ekonomik verimliliğini etkilediğini bildirmiştir.

$\mathrm{Bu}$ nedenle birim alana düşen bitki sayısı ile tanımlanabilen bitki sıklığının optimizasyonu, baklanın yüksek verimliliğini elde etmek için bir ön koşul ve birim alandaki bitki sayısı tane veriminin önemli bir belirleyicisi olduğundan, ilk verim bileşenidir (Dantuma and Thompson 1983).

Yapılan varyans analizi sonuçlarına göre sıra aralıklarının bakla sayısı, gövde çapı, yüz tane ağırlığı, tane verimi ve yaprak alanına; sıra üzeri mesafelerin bitki boyu, ilk bakla yüksekliği ve tane verimine; yılların bitki boyu, dal sayısı, bakla sayısı, gövde çapı, bakla uzunluğu, yüz tane ağırlığı, tane verimi ve yaprakçık sayısına istatistiki olarak etki ettiği, sıra arası x sıra üzeri interaksiyonunun hiçbir özellikte istatistiki olarak önemli olmadığı tespit edilmiştir (Çizelge 1). Saberi (2015), farklı ekim modelleri için baklanın tepkisini araştırdıkları çalışmada bitki sıklığındaki azalmanın bitkide boğum sayısı, 100 tane ağırlığı, bitki taze ağırlığı, bitkide dal ve bakla sayısını arttırdığı; bitki boyu, kuru tane oranı, verim ve baklada tohum sayısını istatistiki olarak önemli etkilemediğini bildirmiştir. Thalji (2010), sera şartlarında baklanın tohum verimi ve agronomik özellikleri üzerine bitki sıklığının (2, 4, 6 bitki/saksı) etkilerini araştırdığı çalışmada, sap ve yaprak kuru ağırlığı, tohum kuru ağırlığı, toplam kuru madde ve sap boyu gibi özellikler için en yüksek değerlerin en fazla bitki sıklığında (6 bitki/saksı) elde edildiğini tespit etmişlerdir.

Khalil et al. (2011), baklanın farklı ekim tarihi ve sıklığında (15.000, 30.000, 45.000, 60.000 bitki/da) yaprak özellikleri, verim ve verim özelliklerindeki değişimini araştırmışlardır. Çalışma sonucunda ekim sıklığının \%50 çiçekleme gün sayısı, yaprak alanı, özel yaprak ağırlığı (yaprak ağırlığı/yaprak alanı), bitkide bakla sayısı ve 100 tane ağırlığını önemli ölçüde etkilediğini tespit etmişlerdir. Dekara 45000 bitki sıklığında verim ve verim özelliklerinin en fazla olduğunu ve bitki sıklığındaki daha fazla artışın yaprak özelliklerini, bitkide bakla sayısını ve tane verimini azalttığını bildirmişlerdir.
Bitkide bakla sayısı sıra aralığından önemli düzeyde $(P<0.05)$ etkilenmiş ancak sıra üzeri mesafeden istatistiki olarak etkilenmemiştir. En yüksek bakla sayısı (14.69 adet/bitki) $75 \mathrm{~cm}$ sıra arası mesafede elde edilmiştir. Sıra arası mesafe daraldıkça bitkide bakla sayısı da azalmıştır. Bitkide bakla sayısı bakımından yıllar arasında istatistiki $(P<0.01)$ fark tespit edilmiştir. Bitkide bakla sayısı ilk yıl daha yüksektir. Nitekim iklim verileri incelendiğinde (Şekil 1) ilk yıl özellikle erken ilkbahar yağışlarının daha fazla olduğu görülmektedir. Bozoğlu (1989), Samsun ekolojik şartlarında farklı zamanlarda ekilen bakla çeşitleri üzerine yaptığı iki yıllık çalışmada çeşit/hatların bitkide bakla sayısının 16.00-21.99 arasında değiştiğini bildirmiştir.

Yüz tane ağırlığı (161.17 g) 75 cm sıra arası mesafede en yüksek olmuştur. Sıra arası mesafe daraldıkça 100 tane ağırığı da azalmıştır. 100 tane ağırlığı bakımından yıllar arasında istatistiki $\quad(P<0.01) \quad$ farklılık belirlenmiştir (Çizelge 1). Della (1988), yapay olarak sulanan ve sadece doğal yağış alan bölgelerde yaptığı çalışmada bakla varyetelerinde 1000 tane ağırlığını 1722-1775 g olarak belirlemiştir. Samsun şartlarında bakla doğal yağışlarla yetiştirilmekte ancak bu denemenin ilk yılında ilkbahar aylarındaki yağış farklılığı tanelerin daha dolgun olmasını sağlayarak bu değeri yükselttiği düşünülmektedir..

Tane verimi sıra aralığından ve yıllardan $\mathrm{P}<0.01$, sıra üzerinden $\mathrm{P}<0.05$ olasılıkla etkilenmiştir. En yüksek tane verimi $25 \mathrm{~cm}$ sıra arası mesafeden elde edilmiştir. Sıra arası mesafe arttıkça verim azalmıştır. Aynı şekilde sıra üzeri mesafe de arttıkça tane verimi azalmıştır. En yüksek tane verimi $15 \mathrm{~cm}$ sıra üzeri mesafeden ve 1. Yll denemesinden alınmıştır. 25 cm sıra aralığında dekarda 20000 bitki bulunurken bu sayı $75 \mathrm{~cm}$ sıra aralığında 6666 adede kadar azalmış ve bu farklılık da verimde kendini göstermiştir. Pilbeam ve ark. (1990), ilkbaharda ekilen bakla (Vicia faba)'ya bitki sıklığının etkisini araştırdıkları çalışmada bitki sıklığı arttıkça verimin de arttığını bildirmişlerdir.

Artık ve Peşken (2006), Samsun ekolojik şartlarında gamma ışınlanmasının M2 generasyonunda bakla (Vicia faba L.)'nın tane verimi ve bazı bitkisel özellikleri üzerine etkileri adındaki çalışmasında 50x20 cm ekim sıklığını kullanmışlardır ve kontrol uygulamasında Filiz 99 bakla çeşidinde ortalama olarak bakla sayısını 
$14.90 \mathrm{adet} / \mathrm{bitki}$, tane verimini $60.54 \mathrm{~g}$ ve 1000 tane ağırlığını $1492.58 \mathrm{~g}$ olduğunu tespit etmiştir. Alan ve Geren (2006) Ödemiş-Izmir koşullarında yetiştirilen bazı bakla (Vicia faba var. major) çeşitlerinin tohum verimi ve diğer bazı özellikleri belirlemek için yaptıkları çalışmada $40 \times 10 \mathrm{~cm}$ ekim sıkığını kullanmışlardır. Çalışma sonucunda iki yılın ortalaması olarak Filiz-99 bakla çeşidinin 1000 tane ağırlığını $1221 \mathrm{~g}$, tane verimini ise $299 \mathrm{~kg} / \mathrm{da}$ olarak tespit etmişlerdir. Yüksek tane verimi, farklı iklim, toprak ve kullanılan genotipe bağlı olarak farklı ekim sıklıklarından elde edilmektedir. Bu nedenle bölge şartları dikkate alınarak ekim sıkığına karar vermek gerekmektedir.

Yaprak alanı sıra aralığından istatistiki olarak $(P<0.05)$ etkilenmiştir. En fazla yaprak alanı 75 $\mathrm{cm}$ sıra aralığından elde edilirken, sıra aralığı daraldıkça yaprak alanı azalmış ve 75 ve $50 \mathrm{~cm}$ sıra aralığı mesafesi istatistiki olarak aynı grupta yer almıştır. Poulain (1984), kışlık baklanın büyüme ve gelişmesi üzerine bitki sıklığının (8, 15,25 and $45 \mathrm{bitki} / \mathrm{m}^{2}$ ) etkilerini araştırdığı çalışmada en yüksek tane veriminin 25 bitki $/ \mathrm{m}^{2}$ 'de elde edildiğini bildirmiştir. Bitki sıklığı arttıkça bitki boyunda ve yaprak alan indeksinde artış, dallanmada azalma olduğunu tespit etmiştir.
Sıra üzeri mesafelerin istatistiki olarak farklılık göstermemesi nedeni ile sıra aralıkları $(25,50,75 \mathrm{~cm})$ ayrı ayrı olmak üzere korelasyon analizine tabi tutulmuştur. Analiz sonucu, tane veriminin $25 \mathrm{~cm}$ sıra aralığında sap kuru madde oranı, bakla kuru madde oranı, bitki boyu ve bakla boyuyla pozitif ve çok önemli; dal sayısı, bakla sayısı, gövde çapı ve 100 tane ağırığıyla önemli; yaprakçık sayısıyla çok önemli ancak negatif ilişkili olduğu tespit edilmiştir. Sıra aralığı $50 \mathrm{~cm}$ olduğunda bakla sayısı, bakla boyu, 100 tane ağırlığıyla çok önemli; bakla kuru madde ve gövde çapıyla önemli ve pozitif, yaprakçık sayısıyla çok önemli ve negatif ilişki belirlenmiştir. Sıra aralığı 75 cm'de dal sayısı, bakla sayısı, gövde çapı, 100 tane ağırlığıyla çok önemli bitki boyu ve bakla boyuyla önemli ve pozitif; yaprakçık sayısıyla çok önemli ve negatif ilişkilidir (Çizelge 2). Her üç sıra arası mesafede verim ile ilişkili özellikler değişirken ortak olan yaprakcık sayısı ile negatif ilişkinin olmasıdır.

Ricciardi (1985), Güney İtalya'da 11 bakla populasyonunda, 12 karakter üzerinde çalışmış ve tohum veriminin bitkide dal, bitkide bakla, salkımda bakla, bitkide tohum sayısı, bitki boyu, 1000 tane ağırlığı ve bakla boyu ile kesin ilişkili olduğunu tespit etmiştir. Sindhu ve ark. (1985),

Çizelge 1. İki yıl süre ile farklı sıra arası ve sıra üzeri mesafede yetiştirilen baklanın bazı özelliklerine ait ortalamaları

Table 1. Averages of some traits of broad bean sown in different intrarow and row spacings

\begin{tabular}{|c|c|c|c|c|c|c|c|}
\hline \multirow{2}{*}{ Özellik } & \multicolumn{3}{|c|}{ Sıra Arası } & \multicolumn{2}{|c|}{ Sıra Üzeri } & \multicolumn{2}{|c|}{ Yıllar } \\
\hline & $25 \mathrm{~cm}$ & $50 \mathrm{~cm}$ & $75 \mathrm{~cm}$ & $15 \mathrm{~cm}$ & $25 \mathrm{~cm}$ & 1. & 2. \\
\hline BB & 76.23 & 75.94 & 77.75 & $79.80 a^{* *}$ & $73.49 \mathrm{~b}$ & $89.36 a^{* *}$ & $63.93 \mathrm{~b}$ \\
\hline DS & 3.07 & 3.21 & 3.24 & 3.19 & 3.15 & $3.46 a^{* *}$ & $2.79 \mathrm{~b}$ \\
\hline İBY & 11.35 & 10.38 & 10.88 & $11.65 a^{* *}$ & $10.09 b$ & 10.56 & 11.17 \\
\hline GÇ & $8.05 \mathrm{~b}$ & $8.30 a b$ & $8.73 a^{*}$ & 8.45 & 8.31 & $8.67 a^{* *}$ & $8.05 b$ \\
\hline BS & 11.57 b & $13.40 \mathrm{ab}$ & $14.69 a^{*}$ & 13.70 & 12.74 & $15.79 a^{* *}$ & $10.65 b$ \\
\hline BU & 11.78 & 11.77 & 11.64 & 11.76 & 11.69 & $12.64 a^{* *}$ & $10.82 b$ \\
\hline BTS & 3.84 & 3.47 & 3.58 & 3.53 & 3.73 & 3.86 & 3.41 \\
\hline YTA & $155.44 \mathrm{~b}$ & $158.50 \mathrm{ab}$ & $161.17 a^{*}$ & 157.79 & 158.96 & $165.04 a^{* *}$ & $151.70 \mathrm{~b}$ \\
\hline TV & 410.98 a & 271.47 b & $197.60 \mathrm{c}$ & $315.74 a^{*}$ & $270.96 \mathrm{~b}$ & $409.13 a^{* *}$ & $177.56 \mathrm{~b}$ \\
\hline YA & 908.72 b & $1168.84 a b$ & $1226.25 a^{*}$ & 1033.87 & 1168.67 & 1078.87 & 1123.76 \\
\hline YS & 103.20 & 116.44 & 125.25 & 110.70 & 119.22 & $77.40 \mathrm{~b}$ & $152.52 a^{* *}$ \\
\hline YKMO & 16.79 & 17.81 & 17.17 & 17.62 & 16.88 & 16.98 & 17.53 \\
\hline SKMO & 22.82 & 21.14 & 21.31 & 21.81 & 21.71 & 22.74 & 20.78 \\
\hline BKMO & 20.08 & 18.79 & 19.41 & 19.67 & 19.19 & 20.79 & 18.07 \\
\hline
\end{tabular}

BB, DS, İBY, GÇ, BS, BU, BTS, YTA, TV, YA, YS, YKMO, SKMO, BKMO = sırasıyla; bitki boyu(cm), dal sayısı, ilk bakla yüksekliği $(\mathrm{cm})$, gövde çapı $(\mathrm{mm})$, bakla sayısı, bakla uzunluğu $(\mathrm{cm})$, baklada tane sayısı, yüz tane ağırlığı $(\mathrm{g})$, tane verimi $(\mathrm{kg} / \mathrm{da})$, yaprak alanı (cm2), bitkide yaprakçık sayısı, yaprak kuru madde oranı $(\%)$, sap kuru madde oranı (\%), bakla kuru madde oranı (\%)

* ${ }^{* *}$ Sırasıyla istatistiksel olarak 0.05 ve 0.01 düzeyinde önemli.

$B B, D S$, IBY, GÇ, BS, BU, BTS, YTA, TV, YA, YS, YKMO, SKMO, BKMO= plant height, first pod height, diametter of stem, number of pods per plant, pod length, number of seeds per pod, 100 seed weight, seed yield, leaf area, number of leaflet per plant, dry matter rate in leaf, dry matter rate in stem, dry matter in pod, respectively

*, ** Significantly different from each other at 0.05 and 0.01 levels, respectively. 


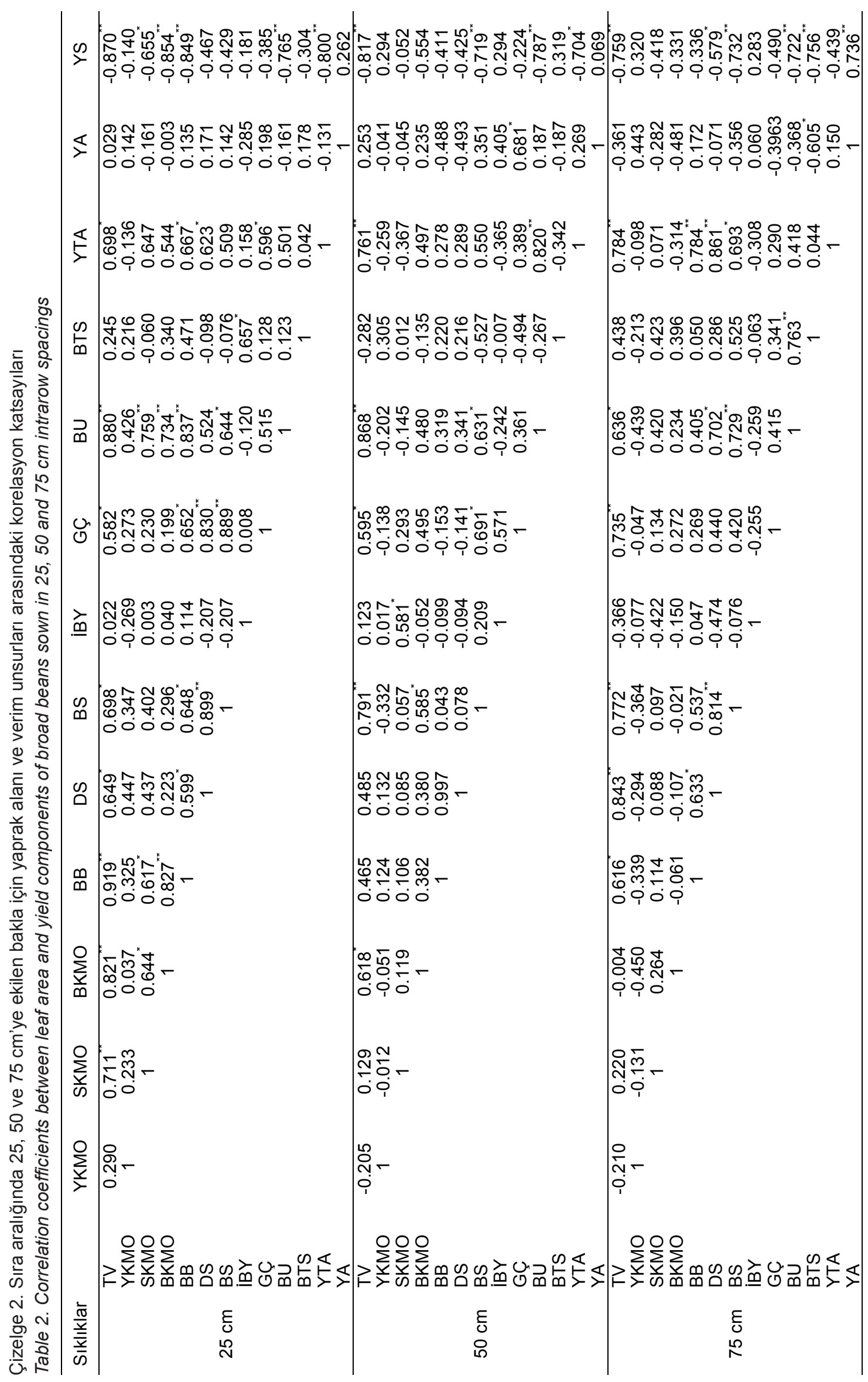


bitkide tohum verimi ve 9 özellik arasındaki ilişkileri belirlemek için yaptıkları çalışmada bitkide dal, tohum ve bakla sayısının tohum verimi ile olumlu ve önemli ilişkileri olduğunu tespit etmişlerdir. Bitkide ana dal sayısı ve bitkide bakla sayısı özelliklerinin verime doğrudan ve pozitif etkisinin olmadığını bildirmektedirler. Kıtıkı ve Açıkgöz (1994), tane verimi ile bitki boyu, ana dal sayısı, bakla sayısı ve tane sayısı arasında pozitif ve önemli ilişkiler bulunduğunu bildirmişlerdir.

Peşken (2006), bakla (Vicia faba L.)'da özellikler arasındaki ilişkiler ve tane verimi bakımından seleksiyon kriterlerinin belirlenmesi adlı çalışmasında 50x20 ekim sıklığını kullanmıştır. Çalışma sonucunda tane verimi ile hasat indeksi, bakla uzunluğu, baklada tane sayısı ve biyolojik verim arasında olumlu ve çok önemli; çiçeklenme süresi, hasat olgunluk süresi, ilk bakla bağlama süresi ve bitki başına dal sayısı ile olumsuz ilişkiler gösterdiğini bildirmiştir.

\section{Sonuç}

Yaprak alanının $25 \mathrm{~cm}$ sıra arası mesafede hiçbir özellik ile istatistiki ilişkisi belirlenmez iken, $50 \mathrm{~cm}$ sıra arsında gövde çapı ile pozitif, $75 \mathrm{~cm}$ sıra arasında ise baklada tane sayısı ile negatif ve önemli ilişsisi tespit edilmiştir (Çizelge 2). Yaprak alanı ile pozitif ilişkili olup yalnızca $75 \mathrm{~cm}$ sıra arası mesafede istatistiki olarak önemli olan yaprakçık sayılarına bakıldığında ise bu özelliğin her üç sıra arası mesafede de tane verimi, yüz tane ağırlığı gibi verimi etkileyen özellikler ile negatif ilişkili olduğu görülmüştür. Bu verilerde path analizi yaparak yaprak alanına dolaylı etkileri olan özellikler belirlendiğinde daha kolay açıklama yapılabileceği ve yaprak alanından çok fotosentetik mekanizma ve bu işlem sonucu meyve-taneye taşınma mekanizmasının baklagillerde nasıl olduğu ve buna etki eden mekanizmaların araştırııp incelenmesi gerektiğini göstermektedir.

\section{Kaynaklar}

Akçin A., 1988. Yemeklik Dane Baklagiller. Selçuk Üni. Yay.:43, Ziraat Fak. Yay No:8

Alan Ö. ve Geren H., 2006. Ödemiş-Izmir koşullarında yetiştirilen bazı bakla (Vicia faba Var. Major) çeşitlerinin tohum verimi ve diğer bazı özellikleri üzerinde bir araştırma. Ege Üniv. Ziraat Fak. Derg., 43(1): 13-20

Albayrak S., Türk M. and Yüksel O., 2011. Effect of row spacing and seeding rate on hungarian vetch yield and quality. Turkish J. Field Crops, 16 (1): $54-58$
Artık C. ve Peşken E., 2006. Gama işınlamasının $\mathrm{m}^{2}$ generasyonunda bakla (Vicia faba L.)'nın tane verimi ve bazı bitkisel özellikleri üzerine etkileri. OMÜ Zir. Fak. Dergisi, 21(1): 95-104.

Bozoğlu H., 1989. Samsun ekolojik şartlarında farklı zamanlarda ekilen bakla çeşitlerinin gelişme durumları ve verimleri üzerine bir araştırma. Yüksek Lisans Tezi, Ondokuz Mayıs Üniversitesi, Fen Bilimleri Enstitüsü, s. 83

Ciampitti I.A. and Vyn T.J., 2011. A comprehensive study of plant density consequences on nitrogen uptake dynamics of maize plants from vegetative to reproductive stages. Field Crop Res, 121:2-18

Dantuma G. and Thompson R., 1983. Whole-crop physiology and yield components. The Faba Bean (Vicia faba L.), (Editor: Hebblethwaite PD), Butterworths Publisher, London, p.143158

Della A., 1988. Characteristics and variation of Cyprus faba bean germplasm. FABIS Newletters, 21:9-12

Erdoğan C., 2012. A leaf area estimation model for faba bean (Vicia faba L.) grown in the Mediterranean type of climate. Süleyman Demirel Üni. Ziraat Fak. Dergisi, 7(1): 58-63

FAO 2013. http://faostat.fao.org/site/567/ DesktopDefault.aspx?PagelD=567\#ancor, (Erişim tarihi: 14.06.2015)

Khalil S.K., Wahab A., Khan A. and Khan A.Z., 2011. Variation in leaf traits, yield and yield components of faba bean in response to planting dates and densities. Egypt. Acad. J. Biolog. Sci., 2(1): 35-43

Kıtıkı A. ve Açıkgöz N., 1994. Baklada verime katkısı olan özelliklerin katkı paylarının belirlenmesi. I. Tarla Bitkileri Kongresi, 25-29 Nisan 1994, İzmir, 112-115

Loss S.P., Siddique K.H.M., Martin L.D. and Crombie A., 1998. Responses of faba bean (Vicia faba L.) to sowing rate in SouthWestern Australia. Part II: Canopy development, radiation absorption and dry matter partitioning. Aust. J. Agric. Res, 49: 999-1008.

Özdemir S., 2002. Yemeklik Baklagiller. Hasad Yayıncılık Ltd. Şti

Pandey S.K. and Singh H., 2011. A simple, costeffective method for leaf area estimation. Journal of Botany, 2011: 6

Peşken E., 2006. Bakla (Vicia faba L.)'da özellikler arasındaki ilişkiler ve tane verimi bakımından seleksiyon kriterlerinin belirlenmesi. OMÜ Zir. Fak. Dergisi, 22(1): 73-78 
Pilbeam C.J., Duc G. and Hebblethwaite P.D., 1990. Effects of plant population density on springsown field beans (Vicia faba) with different growth habits. The J. of Agricultural Science, 114(1): 19-33

Poulain D., 1984. Influence of density on the growth and development of winter field bean (Vicia faba). Vicia faba: Agronomy, Physiology and Breeding World Crops: Production, Utilization, Description, 10: 159-167

Rafiei M., 2009. Influence of tillage and plant density on mungbean. Am.-Eurasian J. Sustain. Agric., 3(4): 877-880

Ricciardi L., 1985. Variability of biological and agronomic characters in accessions of Vicia faba L. Annali della Facolta di Agraria, Universita di Bari, 32: 119-144
Saberi A., 2015. Response of faba bean (Vicia faba L.) to different planting pattern; an overview. Journal of Natural Sciences, 3(1): 1-6

Sindhu J.S., Singh O.P. and Singh K.P., 1985. Component analysis of the factors determining grain yield in faba bean (Vicia faba L.). FABIS-Newletter ICARDA. Faba Bean Information Service. 13:3-5

Thalji T., 2010. Effect of plant density on seed yield and agronomic characters of faba bean (Vicia faba L.) under green house conditions. Bioscience Research, 7(1): 22-25 